\title{
Modulation of cell proliferation, survival and gene expression by RAGE and TLR signaling in cells of the innate and adaptive immune response: role of p38 MAPK and NF-KB
}

\author{
Marcell Costa de MEDEIROS, Sabrina Cruz Tfaile FRASNELLI, Alliny de Souza BASTOS, Silvana Regina Perez \\ ORRICO, Carlos ROSSA JUNIOR
}

Department of Diagnosis and Surgery, School of Dentistry, UNESP - Univ. Estadual Paulista, Araraquara, SP, Brazil.

Corresponding address: Carlos Rossa Junior - Faculdade de Odontologia de Araraquara, Departamento de Diagnóstico e Cirurgia - Rua Humaitá, 1680 Centro - 14801-903 - Araraquara - SP - Brazil - Phone/Fax: +551633016369 - e-mail: crossajr@foar.unesp.br

Submitted: November 22, 2013 - Modification: January 28, 2014 - Accepted: February 13, 2014

ABSTRACT

bjective: The aim of this study was to evaluate a possible synergism between AGE-
RAGE and TLR4 signaling and the role of $\mathrm{p} 38$ MAPK and NF-kB signaling pathways on
the modulation of the expression of inflammatory cytokines and proliferation of cells from
the innate and adaptive immune response. Material and Methods: T lymphocyte (JM) and
monocyte (U937) cell lines were stimulated with LPS and AGE-BSA independently and
associated, both in the presence and absence of p38 MAPK and NF-kB inhibitors. Proliferation
was assessed by direct counting and viability was assessed by a biochemical assay of
mitochondrial function. Cytokine gene expression for RAGE, CCL3, CCR5, IL- 6 and TNF- $\alpha$
was studied by RT-PCR and RT-qPCR. Results: RAGE mRNA expression was detected in
both cell lines. LPS and AGE-BSA did not influence cell proliferation and viability of either
cell line up to 72 hours. LPS and LPS associated with AGE induced expression of IL- 6 and
TNF- $\alpha$ in monocytes and T cells, respectively. Conclusions: There is no synergistic effect
between RAGE and TLR signaling on the expression of IL-6, TNF- $\alpha$, RAGE, CCR5 and CCL3
by monocytes and lymphocytes. Activation of RAGE associated or not with TLR signaling
also had no effect on cell proliferation and survival of these cell types.

Keywords: Periodontal diseases. Diabetes mellitus. Innate immunity. Acquired immunity. Advanced glycosylation end products.

\section{INTRODUCTION}

Diabetes is a metabolic dysfunction that has elevated blood glucose as the hallmark characteristic. The circulating glucose interacts with several proteins in the plasma leading to the formation of advanced glycation end products (AGEs). These AGEs can exert numerous biological effects and their accumulation was demonstrated in kidney ${ }^{18}$, atherosclerotic plaques 6 , heart ${ }^{2}$ and other sites affected by complications associated with diabetes. AGEs exert their effects by binding to their membrane receptor, RAGE (receptor for advanced glycation end-products). This receptor is able to interact with multiple distinct ligands, acting sometimes as a receptor for molecular pattern recognition similar to that involved in innate immune response ${ }^{17}$. In the periodontium, the expression of RAGE has been shown in the endothelium and the basal and spinous layers of the epithelium of the sulcus, associated with inflammation. Furthermore, gene expression of RAGE is significantly higher in the gingival epithelium of patients with diabetes ${ }^{12}$. Expression of RAGE in immune cells has also been reported, however there is paucity of information on regulation of RAGE gene expression in these cells ${ }^{1}$.

Activation of RAGE signaling involves several downstream intracellular signaling pathways, including some that are considered relevant for the expression of inflammatory mediators, such as nuclear factor kappa B (NF-kB) and mitogenactivated protein kinases (MAPK), including $c$-Jun 
N-terminal kinase (JNK), extracellular-regulated kinase (ERK) and p38 $8^{11}$. RAGE expression is also induced by activation of NF-kB, creating a loop that increases upregulation of inflammatory response ${ }^{16}$.

The onset of type 2 diabetes is related to obesity and a basal chronic state of inflammation with increased expression of inflammatory mediators such as TNF- $\alpha$ and IL- 6 by macrophages present in adipose tissues. This augmented inflammatory state eventually results in the development of insulin resistance and hyperglycemia ${ }^{28}$. The activation of transcription factors NF-kB and AP-1 (activating protein 1) plays a fundamental role in regulating gene expression of inflammatory mediators through the activation of NF-kB and MAPKinases, respectively. It is interesting to note that innate immunity signaling via TLRs (particularly TLR4) may play an important role in the establishment and development of diabetes complications ${ }^{13}$.

Chemokine receptor 5 (CCR5) was first recognized as a co-receptor used by HIV virus for entry into immune cells, but its functions in the host response have been expanded and CCR5 is currently considered of relevance in various inflammatory processes such as atherosclerosis, one of the classic complications of diabetes ${ }^{12}$. Recently, its relevance in the progression of periodontal disease was demonstrated in vivo with the use of biochemical inhibitor (Met-RANTES) that significantly reduced the inflammatory infiltrate and alveolar bone resorption ${ }^{21}$. Chemokine (CC motif) ligand 3 (CCL3), also known as macrophage inflammatory protein 1-alpha (MIP-1 $\alpha$ ), is produced primarily by monocytes and activated CD $4+T$ cells and interacts with the chemokine receptors CCR1 and $\mathrm{CCR} 5{ }^{23}$. CCL3 primary function is chemotactic attraction of monocytes and lymphocytes, and its expression is increased in inflamed sites ${ }^{15}$. Higher levels of CCL3 are found in the gingival crevicular fluid of patients with periodontal disease compared with the gingival crevicular fluid from periodontally healthy patients ${ }^{25}$.

Periodontal disease is a chronic inflammatory condition of infectious origin characterized by a dense infiltrate of lymphocytes that is considered one of the classic complications of diabetes. Since most of the observed tissue damage in periodontal disease is attributed to the host response to the bacterial challenge and considering the marked effects of diabetes on the host immune response, as indicated by reduced resistance to infections, our objective was to determine if there is some type of interaction between RAGE and TLR signaling in cells of the innate and adaptive immune response.

\section{MATERIAL AND METHODS}

\section{Cells and materials}

We used established human cell lines of $\mathrm{T}$ lymphocytes (JM) and monocytes (U937) that were grown in RPMI-1640 supplemented with $10 \%$ heat-inactivated fetal bovine serum (FBS), $100 \mathrm{U} / \mathrm{mL}$ penicillin and streptomycin $100 \mu \mathrm{g} / \mathrm{mL}$ at $37^{\circ} \mathrm{C}$ in humidified atmosphere of air and $5 \%$ $\mathrm{CO}_{2}$. Prior to stimulation in the gene expression studies, the cells were routinely de-induced for $8 \mathrm{~h}$ in low (1\%) FBS-containing culture medium. Lipopolysaccharide from Escherichia coli (serotype O55:B5) was purchased from Sigma-Aldrich (St Louis, MO, USA) and was diluted in PBS ( $\mathrm{pH} 7.4)$ to $10 \mathrm{mg} / \mathrm{mL}$. Biochemical inhibitor of p38 MAPK, SB203580, was purchased from Cell Signaling (Danvers, MA, USA). PMA (Phorbol 12-myristate 13-acetate), Doxorubicin hydrochloride and the NF-kB inhibitor Bay 11-7082 were purchased from Sigma-Aldrich (St Louis, MO, USA). Cell culture medium and supplements were purchased from Invitrogen (Life Sciences Corp.).

\section{Preparation of advanced glycation end- product (AGE) \\ Bovine serum albumin - fraction $V$ (BSA) was} diluted in PBS ( $\mathrm{pH} 7.4)$ at a concentration of 50 $\mathrm{mg} / \mathrm{ml}$ and subsequently incubated at $37^{\circ} \mathrm{C}$ for 8 weeks with $0.5 \mathrm{M}$ glucose in $0.2 \mathrm{M}$ phosphate buffer (PBS) $\mathrm{pH} 7.4$ containing $0.5 \mathrm{mM}$ EDTA. The free glucose remaining after this incubation was removed by extensive dialysis $(12 \mathrm{~h}$ ) in PBS free of $\mathrm{Ca}$ and $\mathrm{Mg}, \mathrm{pH}$ 7.4. The BSA-control has been prepared in parallel using the same protocol, except for the addition of $0.5 \mathrm{M}$ glucose. The BSAAGE and BSA control were aliquoted and stored in refrigerator $\left(+4^{\circ} \mathrm{C}\right)$ after confirmation of glycation by determination of absorbance at $405 \mathrm{~nm}$ on a spectrophotometer. Absorbance values over 3.0 in the samples of BSA-AGE and less than 0.1 in samples of BSA-control confirmed the extensive glycation ${ }^{27}$.

\section{Viability and cell proliferation}

For cell proliferation and viability we used the trypan blue dye exclusion assay, JM and U937 cells were plated in medium with $10 \%$ FBS in 48well plates at $5 \times 10^{5}$ cells per well. Analysis of cell viability and apoptosis by the intrinsic pathway by the mitochondrial enzymatic activity assay, cell lines were plated in 96 -well plates at $1 \times 10^{6}$ cells per well. Cells for both assays were stimulated with PBS (negative control), control-BSA (200 ug/mL), AGE-BSA (200 ug/mL), E. coli LPS (100 ng/mL) and the combination of AGE-BSA and LPS E. coli, both in the presence or absence of biochemical inhibitors of p38 MAPK (SB203580, 10 uM) and NF-kB (Bay 
11-7082, $10 \mathrm{uM}$ ). Doxorubicin (10 uM) was used as a positive control for induction of cell death. Stimulations in these experiments were carried out for 24,48 and $72 \mathrm{~h}$.

\section{Quantitative RT-PCR}

JM and U937 cells were plated in low serum RPMI at $1 \times 10^{6}$ cells per well in 48 -well plates. After a de-inducing period of eight hours, the cells were stimulated for 6 hours with BSA-Control, AGE-BSA $(200 \mu \mathrm{g} / \mathrm{mL})$ and LPS E. coli $(100 \mathrm{ng} / \mathrm{mL})$, both alone and associated. These stimulations were performed with and without biochemical inhibitors of p38 MAPK (SB203580, 10 uM) and NF-kB (Bay 11-7082, $10 \mathrm{uM}), 40$ minutes before treatment. PMA (10 uM) was used as a positive control. Cells were collected by centrifugation and total RNA was extracted using an affinity column system, according to the instructions of the supplier (RNAqueous, Ambion Inc). Concentration was determined by the absorbance at $260 \mathrm{~nm}$ on a microvolume spectrophotometer (NanoVue, GE Healthcare). Samples presenting an A260/A280 ratio between
1.8 and 2.1 were considered acceptably free from contaminants. cDNA was synthesized using random hexamer primers and moloney leukemia virus reverse transcriptase, according to the manufacturer's instructions (High Capacity Reverse Transcription kit, Applied Biosystems). Real-time PCR was performed using TaqMan reagents (Applied Biosystems) and pre-designed and optimized pairs of primers and probe (TaqMan Gene Expression Assays, Applied Biosystems). Selected target genes were RAGE, CCR5 and CCL3. GAPDH was used as a housekeeping gene for normalization of the results. This reaction was performed in a StepOne Plus thermocycler (Applied Biosystems) and the results analyzed by $\Delta(\Delta \mathrm{Ct})$, the method using the thermocycler's software.

\section{Semi-quantitative RT-PCR}

Extraction and purification of total RNA extraction was performed as previously described. The PCR reaction was performed in a MyCycler (BioRad) thermocycler using $2 \mathrm{uL}$ of the RT reaction product on a $25 \mathrm{uL}$ total volume PCR reaction mix

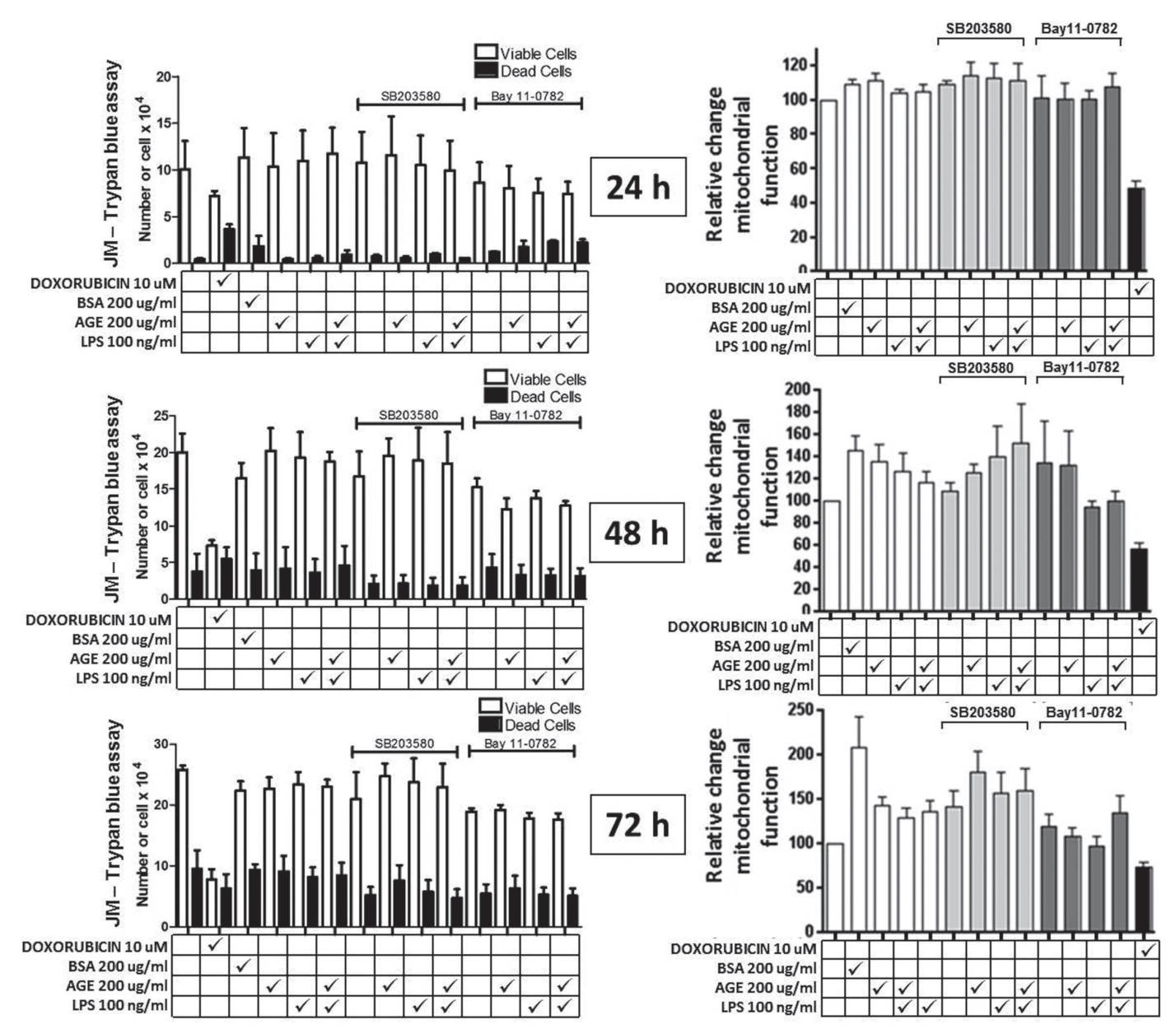

Figure 1- Modulation of cell death in the JM (lymphocyte) cell lineage. Right column corresponds to Trypan Blue Test, and Left column to MTS assay. The cell line was stimulated for 24,48 and 72 hours with E. coli LPS (100 ng/mL) with or without AGE-BSA $(200 \mu \mathrm{g} / \mathrm{mL})$ in the presence and absence of p38 MAPK inhibitors (SB203580, $10 \mu \mathrm{M})$ and NF-kB (Bay 11-7082, $10 \mu \mathrm{M})$. Bars indicate mean \pm standard deviation of three independent experiments 
(Promega) in the presence of $100 \mathrm{pmol} / \mathrm{uL}$ of each gene's primers ( $50 \mathrm{pmol} / \mathrm{uL}$ of sense and antisense primers) for IL-6, TNF-a and GAPDH genes yielding products of 408,313 and 420 bp, respectively. The primer pairs used for IL-6 - (accession no.: NM000600, annealing temperature $-54^{\circ} \mathrm{C}$ ) was: sense 5'- AAAGAGGCACTGGCAGAAAA -3'; antisense 5' - GAGGTGCCCATGCTACATTT - 3'; for TNF- $\alpha$ (accession no.: NM000594, annealing temperature $-55^{\circ} \mathrm{C}$ ) was: sense $5^{\prime}$-TGAGGTACAGGCCCTCTGAT -3', antisense 5'- TGAGGTACAGGCCCTCTGAT - 3', for GAPDH (accession no.: NM002046, annealing temperature $54^{\circ} \mathrm{C}$ ) was sense $5^{\prime}-$ GTCAGTGGTGGACCTGACCT - 3'; antisense 5'AGGGGTCTACATGGCAACTG - 3'. The PCR products were resolved by electrophoresis on $1.5 \%(\mathrm{w} / \mathrm{v})$ agarose gels containing ethidium bromide $(0.5 \mu \mathrm{g} /$ $\mathrm{mL}$ ). Digital images of the gels under UV light were obtained on a gel documentation system (Image Quant 100 - GE Healthcare) and densitometry analysis of the bands corresponding to the PCR products was performed using Image J $1.32 \mathrm{j}$ software (National Institute of Health, USA http:// rsb.info.nih.gov/ij/). The density of the bands corresponding to IL- 6 and TNF- $\alpha$ was normalized to the density of the bands for the housekeeping gene GAPDH and expressed as fold change over unstimulated control.

\section{Statistical analysis}

Data are presented as mean \pm standard deviation and mean \pm standard error specified in the captions of the images. The statistical analysis consisted of unpaired Student's t test to compare the results according to the different stimulations. The calculations were performed on the statistical program GraphPad version 5.00 (La Jolla, CA, USA), using a significance level of $95 \%(p<0.05)$.

\section{RESULTS}

\section{Proliferation and cell death}

Stimulation with BSA-AGE or LPS, alone or associated, did not influence viability of both

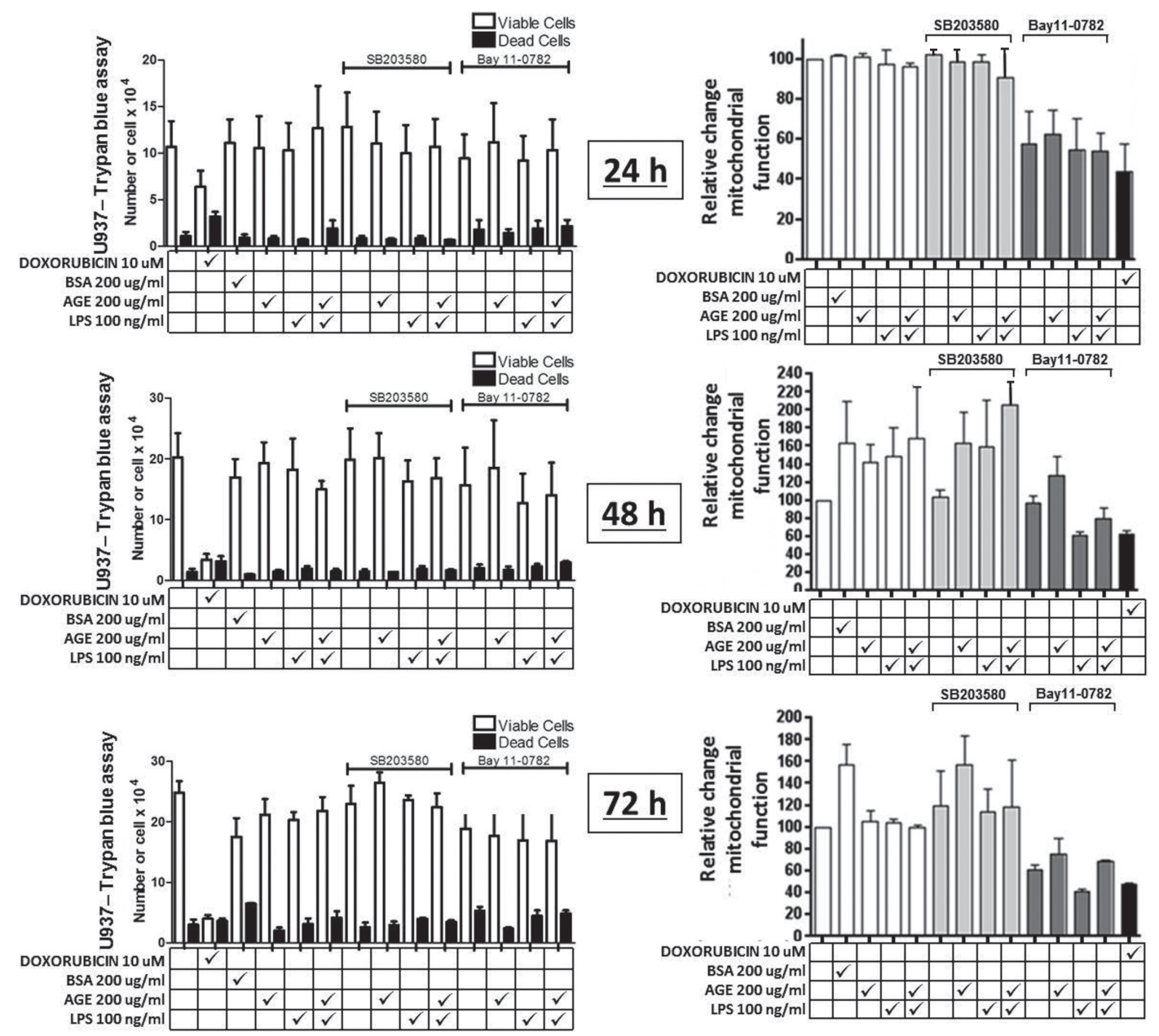

Figure 2- Modulation of cell death in the U937 (monocyte) cell lineage. Right column corresponds to Trypan Blue Test, and left column to MTS assay. The cell line was stimulated for 24,48 and 72 hours with E. coli LPS (100 ng/mL) with or without AGE-BSA $(200 \mu \mathrm{g} / \mathrm{mL})$ in the presence and absence of p38 MAPK inhibitors (SB203580, $10 \mu \mathrm{M})$ and NF-kB (Bay 11-7082, $10 \mu \mathrm{M})$. Bars indicate mean \pm standard deviation of three independent experiments 

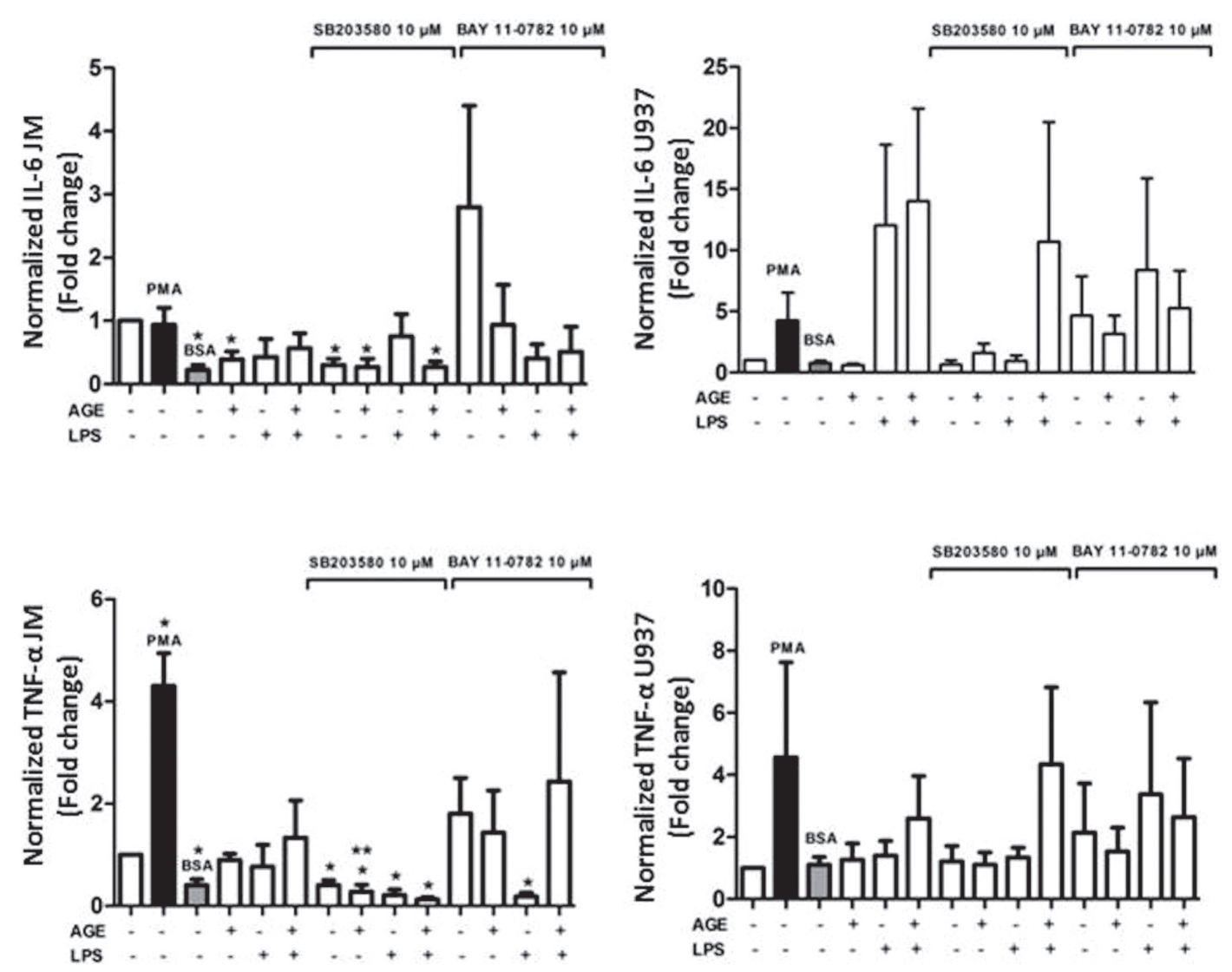

Figure 3- Gene expression (mRNA) of IL- 6 and TNF- $\alpha$ evaluated by RT-PCR on human cell lines of T lymphocytes (JM) and monocytes (U937) after stimulation for $6 \mathrm{~h}$ with E. coli LPS (100 ng/mL) with or without AGE-BSA $(200 \mathrm{ug} / \mathrm{mL})$ in the presence and absence of p38 MAPK inhibitors (SB203580) and NF-kB (Bay 11-7082) inhibitors. The black bar represents the positive control (PMA, $10 \mathrm{nM}$ ). Bars indicate mean \pm standard error of three independent experiments

$\left.{ }^{*}\right)$ Represents significant difference $p<0.05$ compared with control group

$\left({ }^{\star *}\right)$ Represents significant difference $p<0.05$ in relation to the corresponding group without inhibitor

cell lines as determined by the trypan blue dye exclusion assay. Inhibition of p38 MAPK or NF-kB also had no effect on cell viability of lymphocytes and monocytes. Positive control (doxorubicin) significantly reduced cell viability in all three periods, indicating both the susceptibility of cells to the induction of apoptosis and the sensitivity of the assay. Interestingly, a discrete trend towards an increase in cell survival of lymphocytes after 48 and $72 \mathrm{~h}$ of stimulation with LPS in the presence of SB203580 and Bay 11-7082 (Figure 1) was observed. The intrinsic pathway of apoptosis, assessed by MTS reduction assay, which is indicative of mitochondrial activity, was also not affected by the different stimuli at the 24-hour period, except for the positive control (doxorubicin), which significantly reduced the mitochondrial activity of both cell lines. Stimulation of lymphocytes with LPS (alone or associated with AGE-BSA) for 48 and $72 \mathrm{~h}$ slightly increased metabolic activity in lymphocytes. Interestingly, stimulation of the cells with LPS in the presence of SB203580 increased metabolic activity, whereas the opposite effect is observed in the presence of Bay 11-7082. Induction of apoptosis of lymphocytes by the intrinsic pathway with inhibition of NF-kB is also noted at $72 \mathrm{~h}$ after LPS stimulation. In monocytes, none of the stimuli used induced cell death assessed by either method in any of the experimental periods (24, 48 and $72 \mathrm{~h}$ ), however the positive control (doxorubicin) induced cell death, confirming the sensitivity of cells to the induction of apoptosis. Inhibition of NF-kB reduced viability of monocytes assessed by both methods in all experimental periods $(24,48$ and $72 \mathrm{~h}$ ), independently of stimulation (Figure 2).

\section{Regulation of gene expression - RT-PCR and $\mathrm{RT}$-qPCR}

Expression of RAGE mRNA was detected in both lymphocytes and monocytes, but it was not regulated by any of the treatments and experimental conditions, except for a slight inhibition of gene expression with inhibition of NF-kB (Figure 4).

Expression of IL-6 mRNA was weakly expressed by the lymphocyte cell line and was not modulated by the stimuli. Inhibition of p38 MAPK decreased expression of IL- 6 by this cell line, whereas inhibition of NF-kB tended to increase IL- 6 basal 

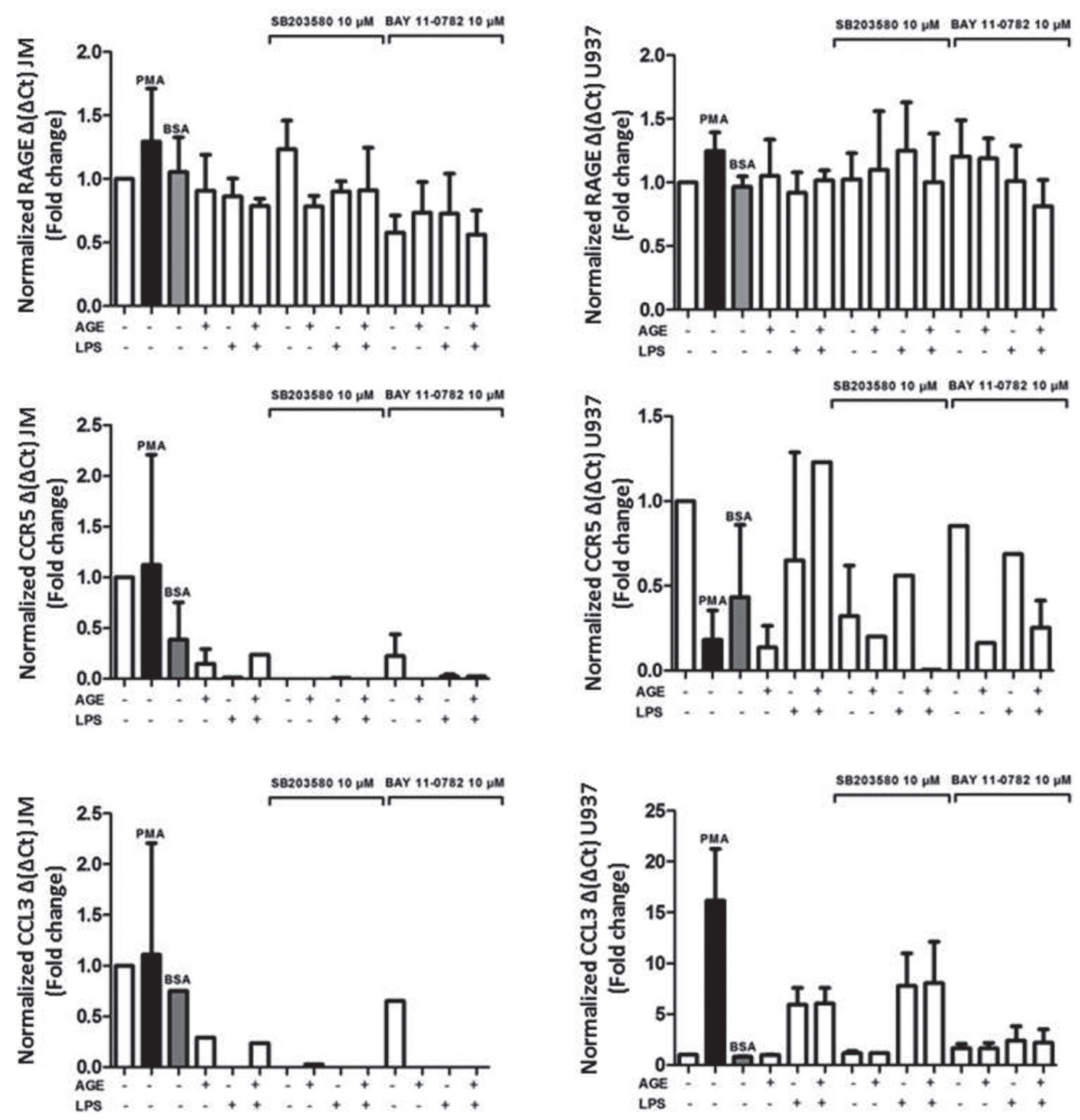

Figure 4- Gene expression (mRNA) for RAGE, CCR5 and CCL3 evaluated by RT-qPCR on cell lines of human T lymphocytes (JM) and monocytes (U937) after a 6-hour stimulation with E. coli LPS (100 ng/mL) with or without AGE-BSA $(200 \mathrm{ug} / \mathrm{mL})$ in the presence and absence of p38 MAPK (SB203580) and NF-kB (Bay 11-7082) inhibitors. Bars indicate mean \pm standard error of three independent experiments

expression and also after stimulation with AGEBSA, but not after stimulation with LPS. This suggests negative regulation of IL- 6 expression by NF-kB (Figure 3). Regulation of TNF- $\alpha$ mRNA was similar to that observed for IL-6, but in contrast to IL-6, TNF- $\alpha$ gene expression was significantly induced by PMA (positive control) in this cell type. A discrete (but not statistically significant) synergistic effect on TNF- $\alpha$ expression is observed upon stimulation with AGE-BSA and LPS. p38 MAPK activity is required for TNF- $\alpha$ expression by lymphocytes. On the other hand, NF-kB was a negative regulator, since inhibition of this pathway increased expression of constitutive and AGE-BSAinduced expression of TNF- $\alpha$, with or without LPS stimulation. Interestingly, LPS-induced expression of TNF- $\alpha$ was dependent on both p38 MAPK and
NF-kB, in a non-redundant manner (Figure 3).

Constitutive expression of IL- 6 mRNA was more marked in monocytes and LPS, but not AGE-BSA, potently induced IL-6 gene expression. LPS-induced IL- 6 was not inhibited by AGE-BSA, indicating absence of antagonistic effect. IL- 6 expression by monocytes is primarily dependent of p38 MAPK, whereas NF-kB does not play an important role (Figure 3). As was observed in lymphocytes, TNF- $\alpha$ gene expression in the monocytic cell line was induced only by PMA (positive control), but not by LPS or AGE-BSA. When these stimuli were associated, there was a discrete (but nonsignificant) synergistic effect on TNF- $\alpha$ expression. p38 MAPK activity was not required for TNF-a expression by these cells; but inhibition of NF-kB resulted in a slight increase in TNF- $\alpha$ mRNA, a negative regulatory effect similar to that observed 
in lymphocytes (Figure 3).

CCR5 and CCL3 are expressed primarily by macrophages/monocyte cells and, as expected, constitutive expression by lymphocytes was low. Interestingly, stimulation with LPS or AGE-BSA inhibited expression of both genes. Inhibition of p38 MAPK and NF-kB virtually abrogated expression of both CCR5 and CCL3 by lymphocytes. In monocytes, expression of CCR5 mRNA was reduced by the stimuli, except when LPS and AGE-BSA were associated. p38 MAPK activity, but not NF-kB, was required for constitutive and $L P S$ associated with AGE-BSA expression of CCR5 (Figure 4). CCL3 gene expression was potently induced by PMA in monocytes. LPS, alone or combined with AGE-BSA, was also a strong inducer of CCL3 $\mathrm{mRNA}$; and this induction was dependent on NF-kB, and not p38 MAPK, activity (Figure 4).

\section{DISCUSSION}

AGE-BSA and LPS, alone or associated, did not induce cell death in human lymphocytes and monocytes. Resistance to apoptosis did not require activation of p38 MAPK or NF-kB. We have not observed a synergistic or antagonistic interaction between the activation of RAGE and TLR4 in these cell lines. Our negative finding is contrary to previous results of a dose-related increase on cell death with increasing concentrations (50, 100,200 and $400 \mathrm{ug} / \mathrm{mL}$ ) of AGE-BSA in the same lymphocytic cell line (JM cells) (10). A 50\% decrease on cell viability (assessed by trypan blue dye exclusion and MTT assays) was observed with the same concentration of AGE-BSA (200 ug/mL). However, the experimental period was 5 days, as opposed to 1, 2 and 3 days in our study. Lower concentrations of AGE-BSA (1, 10 and $100 \mathrm{ug} / \mathrm{mL}$ ) are not capable of inducing apoptosis in human basophils, which was only observed with high concentrations $(1,000 \mathrm{ug} / \mathrm{mL})$ at $48 \mathrm{~h}^{8}$. Activation of RAGE is associated with increased cell survival of eosinophils stimulated with S100B, a RAGE ligand, over a period of 48 hours, which is similar to our findings in the same experimental period ${ }^{5}$. The role of RAGE activation in increased cell survival is also suggested by a report of a positive correlation between the expression of RAGE and cell viability in neoplastic pancreatic cells ${ }^{8}$. Inhibition of p38 MAPK did not modulate apoptosis of T lymphocytes and monocytes in the presence and absence of RAGE and TLR4 agonists, and similar findings are reported in literature in T lymphocytes and monocytes ${ }^{30}$. Our observation of a discrete decrease on cell survival upon inhibition of NF-kB pathway is supported by literature ${ }^{7}$. The activation of TLR4 with LPS from $E$. coli at a concentration of $100 \mathrm{ng} / \mathrm{mL}$ did not increase cell proliferation or cell death and this lack of effect may be related with the concentration of LPS used. Schacter, et al. ${ }^{22}$ (1981) tested the cytotoxicity of $E$. coli LPS in human PBMC using increasing concentrations from 0.2 to $200 \mathrm{ug} / \mathrm{mL}$. Increased cell death was observed initially at $2 \mathrm{ug} / \mathrm{mL}$, with the maximum peak (a modest $11 \%$ of cell death) at $20 \mathrm{ug} / \mathrm{mL}^{22}$.

Both cell lines expressed RAGE mRNA, and this expression was not regulated by the stimuli, but was slightly (although not statistically significantly) dependent on NF-kB in lymphocytes. Even though p38 MAPK was not relevant for regulation of RAGE gene expression, considering that this signaling pathway is activated downstream of RAGE, it may be involved in the biological effects mediated by RAGE activation in both monocytes and in lymphocytes ${ }^{9,24}$.

Constitutive expression of IL- 6 mRNA was detected on $\mathrm{T}$ lymphocytes, and stimulation with AGE-BSA or LPS alone significantly inhibited expression of IL-6; an effect that was not observed when these stimuli were combined. Thus, although we have not observed a synergistic effect between TLR4 and RAGE, the simultaneous stimulation of these receptors eliminated the inhibitory effect on IL-6 gene expression verified when either receptor was activated independently. In monocytes, expression of IL- 6 was higher than in lymphocytes and these cells were also more responsive to stimulation with PMA (positive control) and LPS, but not by AGE-BSA. Interestingly, the simultaneous activation of RAGE and TLR4 resulted in no antagonistic or synergistic effects. Activation of RAGE with AGE-BSA did not modulate expression of IL-6, but it also did not attenuate the induction associated with LPS when the stimuli were associated. Expression of IL- 6 mRNA by both lymphocytes and monocytes was dependent on p38 MAPK pathway but not NF-kB. These data are consistent with other studies evaluating the role of p38 MAPK on IL-6 gene expression in different cell types ${ }^{14,19,20,29}$.

PMA-induced expression of TNF- $\alpha$ in both lymphocytes and monocytes, and simultaneous activation of RAGE and TLR4, resulted in a slight synergistic effect in the induction of TNF- $\alpha$ mRNA in both cell types. p38 MAPK pathway had opposite roles in regulation of TNF- $\alpha$ after simultaneous stimulation with AGE-BSA and LPS: in lymphocytes, inhibition of p38 MAPK decreased expression of TNF- $\alpha$; whereas, in monocytes, inhibition of p38 MAPK caused a slight (but not statistically significant) increase in TNF- $\alpha$ mRNA. In both lymphocytes and monocytes, NF-kB signaling was not relevant for regulation of TNF- $\alpha$ gene expression.

Modulation of expression of the chemokine CCL3 and its receptor CCR5 was evaluated as a 
manner of obtaining information on the effects of activation of TLR4 and RAGE in modulating the interaction between innate and adaptive responses. Expression of CCR5 in T lymphocytes was lower in comparison with monocytes, as expected based on the literature 26,31 . RAGE and TLR4 stimulation, alone and associated, decreased CCR5 gene expression in $T$ lymphocytes, whereas the combined activation of these receptors did not affect CCR5 expression in monocytes. In both cell types, expression of CCR5 was dependent on both p38 MAPK (constitutive and induced by LPS) and NF-kB (only after stimulation with LPS and AGE-BSA associated).

Similarly to CCR5 gene, CCL3 mRNA expression was higher in monocytes. In lymphocytes, as observed for the regulation of CCR5, all stimuli tended to reduce expression of $\mathrm{CCL} 3$, and inhibition of p38 MAPK or NF-kB nearly abrogated expression in these cells. In monocytes, activation of TLR4 caused a marked induction of CCL3 MRNA, and this induction was dependent of NF-kB pathway signaling but not of p38 MAPK activity. Activation of RAGE in monocytes did not regulate CCL3 expression, but when TLR4 and RAGE were simultaneously activated there was no attenuation of the inductive effect of LPS. Other studies have linked the expression of this chemokine with p38 MAPK pathway and NF-kB activation ${ }^{3,4}$.

\section{CONCLUSION}

In conclusion, there was no synergism between RAGE and TLR4 receptors on modulation of cell death and inflammatory gene expression in cell lines of innate (U937) and adaptive (JM) immune response.

\section{ACKNOWLEDGEMENTS}

Financial support was provided by CAPES - Coordination for the Improvement of Higher Education Personnel (\#4638-05), and by FAPESP - São Paulo Research Foundation (Grant \#2010/06589-8) to CRJ.

\section{REFERENCES}

1- Bao W, Min D, Twigg SM, Shackel NA, Warner FJ, Yue DK, et al. Monocyte CD147 is induced by advanced glycation end products and high glucose concentration: possible role in diabetic complications. Am J Physiol Cell Physiol. 2010;299(5):C1212-9. 2- Candido R, Forbes JM, Thomas MC, Thallas V, Dean RG, Burns WC, et al. A breaker of advanced glycation end products attenuates diabetes-induced myocardial structural changes. Circ Res. 2003;92(7):785-92.

3- Chui R, Dorovini-Zis K. Regulation of CCL2 and CCL3 expression in human brain endothelial cells by cytokines and lipopolysaccharide. J Neuroinflammation. 2010;7:1.
4- Chung J, Choi MJ, Jeong SY, Oh JS, Kim HK. Chemokines gene expression of RAW 264.7 cells by Actinobacillus actinomycetemcomitans lipopolysaccharide using microarray and RT-PCR analysis. Mol Cells. 2009;27(2):257-61.

5- Curran CS, Bertics PJ. Human eosinophils express RAGE, produce RAGE ligands, exhibit PKC-delta phosphorylation and enhanced viability in response to the RAGE ligand, S100B. Int Immunol. 2011;23(12):713-28.

6- Forbes JM, Yee LT, Thallas V, Lassila M, Candido R, Jandeleit-Dahm KA, et al. Advanced glycation end product interventions reduce diabetes-accelerated atherosclerosis. Diabetes. 2004;53(7):1813-23.

7- García MG, Alaniz L, Lopes EC, Blanco G, Hajos SE, Alvarez E. Inhibition of NF-kappaB activity by BAY 11-7082 increases apoptosis in multidrug resistant leukemic T-cell lines. Leuk Res. 2005;29(12):1425-34.

8- Han K, Suzukawa M, Yamaguchi M, Sugimoto N, Nakase Y, Toda $\mathrm{T}$, et al. The in vitro effects of advanced glycation end products on basophil functions. Int Arch Allergy Immunol. 2011;155(Suppl 1):64-70.

9- Hou FF, Ren H, Owen WF Jr, Guo ZJ, Chen PY, Schmidt AM, et al. Enhanced expression of receptor for advanced glycation end products in chronic kidney disease. J Am Soc Nephrol. 2004;15(7):1889-96.

10- Hung LF, Huang KY, Yang DH, Chang DM, Lai JH, Ho LJ. Advanced glycation end products induce $\mathrm{T}$ cell apoptosis: involvement of oxidative stress, caspase and the mitochondrial pathway. Mech Ageing Dev. 2010;131(11-12):682-91.

11- Jandeleit-Dahm K, Watson A, Soro-Paavonen A. The AGE/RAGE axis in diabetes-accelerated atherosclerosis. Clin Exp Pharmacol Physiol. 2008;35(3):329-34.

12- Katz J, Bhattacharyya I, Farkhondeh-Kish F, Perez FM, Caudle RM, Heft MW. Expression of the receptor of advanced glycation end products in gingival tissues of type 2 diabetes patients with chronic periodontal disease: a study utilizing immunohistochemistry and RT-PCR. J Clin Periodontol. 2005;32(1):40-4.

13- Kim HK, Park HR, Sul KH, Chung HY, Chung J. Induction of RANTES and CCR5 through NF-kappaB activation via MAPK pathway in aged rat gingival tissues. Biotechnol Lett. 2006;28(1):17-23. 14- Lappas M, Permezel M, Rice GE. Advanced glycation endproducts mediate pro-inflammatory actions in human gestational tissues via nuclear factor-kappaB and extracellular signal-regulated kinase 1/2. J Endocrinol. 2007;193(2):269-77. 15- Lee SC, Brummet ME, Shahabuddin S, Woodworth TG, Georas SN, Leiferman KM, et al. Cutaneous injection of human subjects with macrophage inflammatory protein-1 alpha induces significant recruitment of neutrophils and monocytes. J Immunol. 2000;164(6):3392-401.

16- Liliensiek B, Weigand MA, Bierhaus A, Nicklas W, Kasper M, Hofer $S$, et al. Receptor for advanced glycation end products (RAGE) regulates sepsis but not the adaptive immune response. J Clin Invest. 2004;113(11):1641-50.

17- Neeper M, Schmidt AM, Brett J, Yan SD, Wang F, Pan YC, et al. Cloning and expression of a cell surface receptor for advanced glycosylation end products of proteins. J Biol Chem. 1992; 267(21):14998-5004.

18- Oldfield MD, Bach LA, Forbes JM, Nikolic-Paterson D, McRobert $A$, Thallas $V$, et al. Advanced glycation end products cause epithelial-myofibroblast transdifferentiation via the receptor for advanced glycation end products (RAGE). J Clin Invest. 2001;108(12):1853-63.

19- Qian Y, Deng J, Xie H, Geng L, Zhou L, Wang Y, et al. Regulation of TLR4-induced IL-6 response in bladder cancer cells by opposing actions of MAPK and PI3K signaling. J Cancer Res Clin Oncol. 2009;135(3):379-86. 
20- Rasheed Z, Akhtar N, Haqqi TM. Advanced glycation end products induce the expression of interleukin- 6 and interleukin- 8 by receptor for advanced glycation end product-mediated activation of mitogen-activated protein kinases and nuclear factorkB in human osteoarthritis chondrocytes. Rheumatology (Oxford). 2011;50(5):838-51.

21- Repeke CE, Ferreira SB Jr, Vieira AE, Silveira EM, AvilaCampos MJ, Silva JS, et al. Dose-response met-RANTES treatment of experimental periodontitis: a narrow edge between the disease severity attenuation and infection control. PloS One. 2011;6(7):e22526.

22- Schacter B, Kleinhenz ME, Edmonds K, Ellner JJ. Spontaneous cytotoxicity of human peripheral blood mononuclear cells for the lymphoblastoid cell line CCRF-CEM: augmentation by bacterial lipopolysaccharide. Clin Exp Immunol. 1981;46(3):640-8.

23- Sharma V, Xu M, Ritter LM, Wilkie NM. HIV-1 tat induces the expression of a new hematopoietic cell-specific transcription factor and downregulates MIP-1 alpha gene expression in activated T-cells. Biochem Biophys Res Commun. 1996;223(3):526-33. 24- Takahashi HK, Mori S, Wake H, Liu K, Yoshino T, Ohashi K, et al. Advanced glycation end products subspecies-selectively induce adhesion molecule expression and cytokine production in human peripheral blood mononuclear cells. J Pharmacol Exp Ther. 2009;330(1):89-98.

25- Tymkiw KD, Thunell DH, Johnson GK, Joly S, Burnell KK, Cavanaugh $\mathrm{JE}$, et al. Influence of smoking on gingival crevicular fluid cytokines in severe chronic periodontitis. J Clin Periodontol. 2011;38(3):219-28.
26- Ubogu EE, Callahan MK, Tucky BH, Ransohoff RM. CCR5 expression on monocytes and $T$ cells: modulation by transmigration across the blood-brain barrier in vitro. Cell Immunol. 2006;243(1):19-29.

27- Valencia JV, Weldon SC, Quinn D, Kiers GH, DeGroot J, TeKoppele JM, et al. Advanced glycation end product ligands for the receptor for advanced glycation end products: biochemical characterization and formation kinetics. Anal Biochem. 2004;324(1):68-78.

28- Wang P, Mariman E, Renes J, Keijer J. The secretory function of adipocytes in the physiology of white adipose tissue. J Cell Physiol. 2008;216(1):3-13.

29- Wang X, Xue H, Xu Q, Zhang K, Hao X, Wang L, et al. p38 kinase/cytosolic phospholipase $A 2 /$ cyclooxygenase-2 pathway: a new signaling cascade for lipopolysaccharide-induced interleukin1 beta and interleukin- 6 release in differentiated U937 cells. Prostaglandins Other Lipid Mediat. 2008;86(1-4):61-7. 30- Wang Y, Zeigler MM, Lam GK, Hunter MG, Eubank TD, Khramtsov VV, et al. The role of the NADPH oxidase complex, p38 MAPK, and Akt in regulating human monocyte/macrophage survival. Am J Respir Cell Mol Biol. 2007;36(1):68-77.

31- Wierda RJ, Kuipers HF, van Eggermond MC, Benard A, van Leeuwen JC, Carluccio S, et al. Epigenetic control of CCR5 transcript levels in immune cells and modulation by small molecules inhibitors. J Cell Mol Med. 2012;16(8):1866-77. 